\title{
Original Research Article \\ Biomarkers as a diagnostic tool in primary and secondary dengue Infections
}

\author{
Chandola I. ${ }^{1}$, Sitara B. ${ }^{2}$, Negi N. ${ }^{3}$, Kataria V.K. ${ }^{4}$ \\ ${ }^{1}$ Dr. Iva Chandola, Assistant Professor, ${ }^{2}$ Dr. Brahmnish Sitara, P.G. Resident, ${ }^{3}$ Dr. Nidhi Negi, Associate Professor, \\ ${ }^{4}$ Dr. V. K. Kataria, Professor \& Head, all authors are affiliated with Department of Microbiology, Shri Guru Ram Rai \\ Institute of Medical \& Health Sciences and Shri Mahant Indiresh Hospital, Dehradun, Uttarakhand, India.
}

Corresponding Author: Dr. Nidhi Negi, Associate Professor, Department of Microbiology, Shri Guru Ram Rai Institute of Medical \& Health Sciences and Shri Mahant Indiresh Hospital, Dehradun (U.K.) India. E-mail: nidhinegi28@gmail.com

\begin{abstract}
Introduction: Dengue virus infection presents with a diverse clinical picture ranging from asymptomatic illness to Dengue fever to dengue hemorrhagic fever/dengue shock syndrome. Because of its varied clinical presentation, accurate diagnosis is difficult and relies largely on laboratory confirmation. We therefore designed a prospective study to ascertain the role of biomarkers in cases of serologically confirmed primary and secondary dengue infections. Material \& Methods: A total of 2165 patients presenting to the hospital with acute febrile illness were serologically confirmed to be suffering from dengue infection. Hematological examinationand Liver function test were carried out for all these cases. Results: A total of $1942(89.69 \%)$ patients were classified as having primary dengue infection and only $182(8.4 \%)$ were classified as having secondary dengue infection out of the total seropositive cases (2165).13.16\% of these patients had platelet count below 50,000/ $\mathrm{mm}^{3}$. Majority of the patients showed deranged hepatic function. Amongst the hepatic biomarkers AST and GGT were found to be significantly deranged as compared to other parameters.Also it was found that Alkaline phosphatase levels \&platelet count may serve as early predictors for the differentiation of primary and secondary dengue infection.Conclusion: The study highlights the importance of biochemical markers in distinguishing dengue from other febrile illness and their role in differentiating primary and secondary dengue cases.
\end{abstract}

\section{Introduction}

The World Health Organization (WHO) considers dengue as a major global public health challenge in the tropic and subtropic nations. Dengue has seen a major upsurge worldwide due to increased population growth rate, global warming, unplanned urbanization, inefficient mosquito control, frequent air travel, and lack of health care facilities [1,2]. Two and a half billion people reside in dengue-endemic regions and roughly 400 million infections occurring per year, with a mortality rate surpassing $5-20 \%$ in some areas $[2,3]$.

Dengue virus infection presents with a diverse clinical picture ranging from asymptomatic illness to DF to the severe illness of dengue hemorrhagic fever/ dengue shock syndrome (DHF/DSS) [1]. Because of its varied clinical presentation, accurate diagnosis is difficult and

Manuscript received: $10^{\text {th }}$ January 2019

Reviewed: $20^{\text {th }}$ January 2019

Author Corrected: $28^{\text {th }}$ January 2019

Accepted for Publication: $31^{\text {st }}$ January 2019 relies largely on laboratory confirmation [4]. Primary infection is often asymptomatic but may result in dengue fever (DF). However secondary infection can lead to life threatening dengue hemorrhagic fever (DHF) / Dengue shock syndrome.

Primary infections are characterized by an increase in dengue specific IgM antibodies 4-5 days after the onset of fever and increased IgG antibodies after 7-10 days. In secondary infections, IgG antibodies rise rapidly even during acute phase. However, there are a number of atypical forms of dengue infection; hepatic dysfunction is a well-recognized feature of dengue infection[5,6].

We designed a prospective study to determine the status of hepatic and hematological parameters in cases of serologically confirmed primary and secondary dengue infections Additionally we also tried to determine which 
of these parameters can serve as early laboratory predictors to differentiate primary from secondary dengue infection before the critical stage is reached.

\section{Material and Methods}

Place of Study: The present study was undertaken at Shri Guru Ram Rai Institute of Medical and Health Sciences by the department of Microbiology from June to September 2018. During this period, 2165 patients presenting to the hospital with acute febrile illness were serologically confirmed to be suffering from dengue infection. Case definition criteria for DF were high fever, fever with rash, retro-orbital pain, myalgia, arthralgia and conjunctival congestion as per WHO guidelines [7].

Type of Study : Prospective cross-sectional study Inclusion Criteria : Case definition of dengue fever as per WHO (2009)[7]

\section{Exclusion Criteria}

1. All the cases which showed negative serology, (or) positive for other causes of fever (malaria, widal, PUO), outpatient cases were excluded from the study.

2. Patients presenting with other co morbid infections along with dengue fever were not included into the study.

3. All the other causes of thrombocytopenia were also excluded from the study.

All the other causes of thrombocytopenia were also excluded from the study.

Seropositivity for dengue fever was determined using Microwell ELISA test for NS1, IgM and IgG using

\section{Original Research Article}

Panbio Dengue Early ELISA, Panbio Dengue Capture, Republic of Korea. Hematological profiles and biochemical investigations of seropositive dengue cases were carried out at the time of admission and were correlated.

Based on the serological markers patients were classified as having primary or secondary dengue infection as follows:

Early primary infection: NS1+++

Late primary infection: $\mathrm{IgM}++, \mathrm{IgG}+/-$

Early secondary infection: IgG++, IgM+/-, NS1++

Late secondary infection: $\operatorname{IgG}++, \operatorname{IgM}+, \mathrm{NS} 1-$

Hematological examination was done using automated analyser DxH500 by Beckman Coulter, California, USA. Hemoconcentration was seen as raised $\mathrm{Hb}$ or RBC count. Leukopenia was defined as less than 4000 /cubic $\mathrm{mm}$ and thrombocytopenia as less than 1.0 lakh/cubic $\mathrm{mm}$. Liver function test was done using Vitros E Cianalyser (Ortho clinical diagnostics, Rochester, NY). Altered liver function was considered if total bilirubin $>2 \mathrm{mg} / \mathrm{dl}$, AST $>60 \mathrm{IU} / \mathrm{L}$, ALT $>45$ IU/L, ALP $>147$ U/L, GGT $>48 \mathrm{U} / \mathrm{L}$, or albumin $<$ $3.5 \mathrm{mg} / \mathrm{dl}$.

Statistical Analysis- Statistical analysis was done using Sofa Stats software (open source statistics, analysis and reporting software from Paton-Simpson\& Associates Ltd).Results were presented as mean and SD for continuous variables while frequency and percentage are given for qualitative variables. Unpaired t-test used for $\mathrm{P}$ values and $95 \%$ confidence interval (CI) were calculated from the mean, SD and number using Med Calc easy to use statistical software. A $p<=0.05$ was considered statistically significant

\section{Results}

Of the 2165 patients found seropositive for DF, 75\% $(n=1627)$ were found positive for NS1Ag alone, 2.9\% ( $n=63)$ only IgM positive, $4.67 \%(\mathrm{n}=101)$ only IgG positive, $11.5 \%(\mathrm{n}=249)$ were found positive for both $\operatorname{NS} 1 \& \operatorname{IgM}, 1.52 \%(\mathrm{n}=33)$ both IgM \& IgG and 3.3\%(n=73) NS1 \& IgG positive and $0.87 \%(n=11)$ positive for all three NS1, IgM, IgG.

Table-1: Distribution of serological markers among dengue positive cases

\begin{tabular}{|c|c|c|}
\hline Serological marker & Number & Percentage \\
\hline NS1 Ag & 1627 & 75 \\
\hline IgM & 63 & 4.9 \\
\hline IgG & 101 & 11.5 \\
\hline NS1 and IgM & 249 & 1.52 \\
\hline IgM \& IgG & 33 & 3.3 \\
\hline NS1\& IgG & 73 & 0.87 \\
\hline NS1, IgM, IgG & 11 & 07 \\
\hline
\end{tabular}

The mean age of patients in our study was 37.2 years with a range of 5-80 yrs. 
Table-2: Age wise distribution of patients

\section{Original Research Article}

\begin{tabular}{|c|c|c|}
\hline Age & Total Cases +VE & Percentage \\
\hline $1-10$ YRS & 108 & 5 \\
\hline $11-20$ YRS & 394 & 32.74 \\
\hline $21-30$ YRS & 709 & 19.12 \\
\hline $31-40$ YRS & 414 & 12.1 \\
\hline $41-50$ YRS & 262 & 7.76 \\
\hline $51-60$ YRS & 168 & 3.83 \\
\hline $61-70$ YRS & 83 & 1.25 \\
\hline$>70$ YRS & 27 & \\
\hline
\end{tabular}

Maximum number of patients belonged to the age group of $21-30$ yrs. There were $62.31 \%(n=1349)$ males and $37.69 \%(n=816)$ females.

Hematological Profile- The mean $( \pm \mathrm{SE})$ of Hemoglobin, Hematocrit, TLC and platelet count at admission were $13.2 \pm 0.20 \mathrm{gm} / \mathrm{dl}, 40.8 \pm 0.5 \%, 5945 \pm 280$ cells $/ \mathrm{mm}^{3}$ and $14.5 \pm 0.5 \times 1000 / \mathrm{mm} 3$ respectively

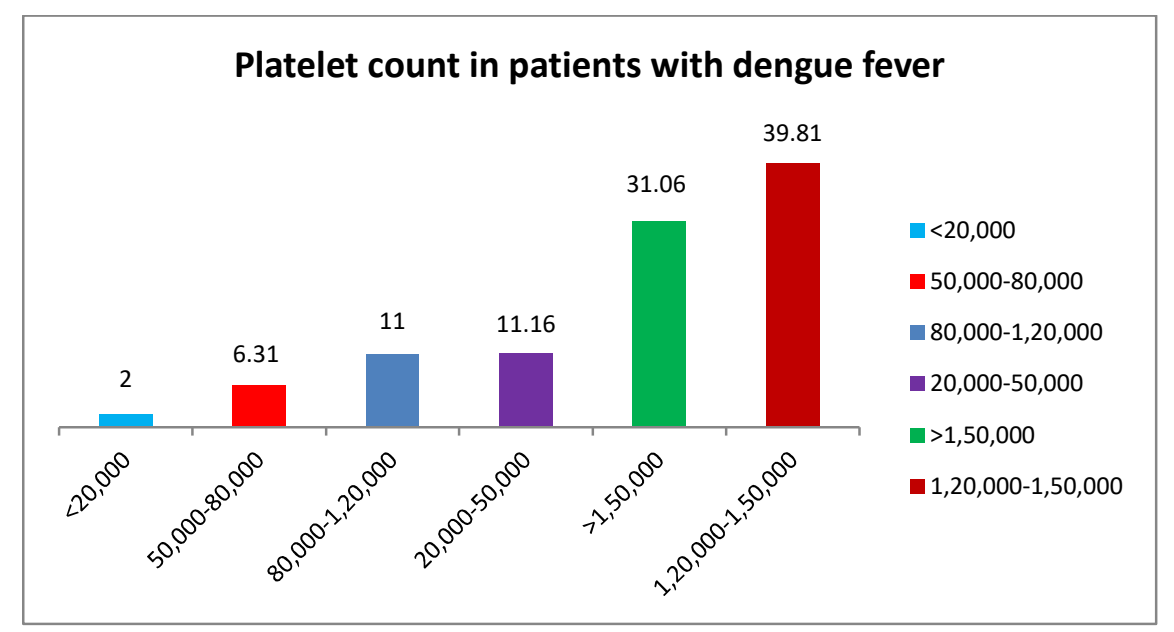

Chart-1: Hematological parameters in patients with dengue fever

Majority of patients (70.87\%) had platelet counts above 1 lac while only $13.16 \%$ of the patients had platelet count below $50,000 / \mathrm{mm}^{3}$.

Liver function test- Hepatic dysfunction, in the form of deranged total bliirubin, AST, ALT, ALP, GGT, albumin and altered albumin globulin ratio was present in $4.12 \%(\mathrm{n}=89), 78.3 \%(\mathrm{n}=1695), 55.6 \%(\mathrm{n}=1203), 8.2 \%(\mathrm{n}=187), 36.1 \%$ $(\mathrm{n}=781), 32 \%(\mathrm{n}=692), 1.03 \%(\mathrm{n}=22)$ of patients respectively.

Table-3: Liver function tests in patients with dengue fever

\begin{tabular}{|c|c|c|c|}
\hline Liver biochemical test & Mean $\pm \mathrm{SE}^{*}$ & Number of patients with>ULN** & P value \\
\hline Total Bilirubin & $1.05 \pm 0.09 \mathrm{mg} / \mathrm{dl}$ & $4.12 \%(89)$ & 0.21 \\
\hline AST & $356.6 \pm 51.2 \mathrm{U} / \mathrm{L}$ & $78.3 \%(1695)$ & 0.02 \\
\hline ALT & $166.2 \pm 31.2 \mathrm{U} / \mathrm{L}$ & $55.6 \%(1203)$ & 0.031 \\
\hline ALP & $90.9 \pm 8.7 \mathrm{U} / \mathrm{L}$ & $8.24 \%(187)$ & 0.62 \\
\hline GGT & $83.8 \pm 6.5 \mathrm{U} / \mathrm{L}$ & $36.1 \%(781)$ & 0.54 \\
\hline Albumin & $3.5 \pm 0.5 \mathrm{mg} / \mathrm{dl}$ & $32 \%(692)$ & 0.032 \\
\hline \multicolumn{3}{|c|}{$\begin{array}{c}\text { NOTE: } \\
* \mathrm{SE}=\text { Standard error } \\
* * \mathrm{ULN}=\text { Upper Limit of Normal }\end{array}$} & \\
\hline
\end{tabular}




\section{Original Research Article}

The mean $( \pm \mathrm{SE})$ of total bilirubin, AST, ALT, ALP, GGT, albumin was $1.05 \pm 0.09 \mathrm{mg} / \mathrm{dl}, 356.6 \pm 51.2 \mathrm{U} / \mathrm{L}$, 166.2 $\pm 31.2 \mathrm{U} / \mathrm{L}, 90.9 \pm 8.7 \mathrm{U} / \mathrm{L}, 83.8 \pm 6.5 \mathrm{U} / \mathrm{L}, 3.5 \pm 0.5 \mathrm{mg} / \mathrm{dl}$ respectively. The number of patients with DF showing rise in AST levels was significantly higher than those showing rise in ALT $(\mathrm{p}<0.0001)$.

Also the number of patients showing elevated levels of GGT was significantly higher than those with elevated levels of ALP $(p<0.001)$. No statistically significant difference was observed in LFT's between male and female patient

Table-4: Comparison of platelet count and liver function tests in patients with primary and secondary dengue fever.

\begin{tabular}{|c|c|c|c|c|c|c|}
\hline \multirow[t]{2}{*}{ Parameters } & \multicolumn{2}{|c|}{$\begin{array}{c}\text { Primary Dengue } \\
\text { Fever }(n=1942)\end{array}$} & \multicolumn{2}{|c|}{$\begin{array}{c}\text { Secondary Dengue } \\
\text { Fever }(n=182)\end{array}$} & \multicolumn{2}{|c|}{ Statistical analysis } \\
\hline & Number & $\%$ & Number & $\%$ & P value & $95 \% \mathrm{CI}$ \\
\hline $\begin{array}{l}\text { Low platelet count } \\
\left(<50,000 \mathrm{~mm}^{3}\right)\end{array}$ & $44 / 182$ & 24.1 & $19 / 24$ & 79.16 & 0.002 & 1.119 to 2.6797 \\
\hline $\begin{array}{l}\text { Total bilirubin raised } \\
\qquad(>2 \mathrm{mg} / \mathrm{dl})\end{array}$ & $9 / 74$ & 2.1 & $8 / 14$ & 57.14 & 0.001 & 3.89 to 21.8382 \\
\hline $\begin{array}{l}\text { AST raised } \\
(60 \mathrm{U} / \mathrm{L})\end{array}$ & $67 / 79$ & 84.8 & $5 / 10$ & 50.0 & 0.0985 & 0.9063 to 3.1746 \\
\hline $\begin{array}{l}\text { ALT raised } \\
(>45 \mathrm{U} / \mathrm{L})\end{array}$ & $40 / 87$ & 4.5 & $5 / 11$ & 45.5 & 0.974 & 0.5092 to 2.0091 \\
\hline $\begin{array}{l}\text { ALP raised } \\
(147 \mathrm{U} / \mathrm{L})\end{array}$ & $7 / 63$ & 11.1 & $3 / 6$ & 50.0 & 0.0055 & 0.0768 to 0.6428 \\
\hline $\begin{array}{c}\text { GGT raised } \\
(>48 \mathrm{U} / \mathrm{L})\end{array}$ & $27 / 63$ & 42.9 & $4 / 7$ & 57.1 & 0.4219 & 0.3717 to 1.5134 \\
\hline $\begin{array}{l}\text { Albumin decreased } \\
(<3.5 \mathrm{mg} / \mathrm{dl})\end{array}$ & $0 / 64$ & $\begin{array}{l}0.0 \\
0.0\end{array}$ & $0 / 7$ & 0.0 & 0.2863 & 0.0026 to 5.7872 \\
\hline
\end{tabular}

A comparison was also made of the hematological and hepatic functional derangements in patients with primary and secondary dengue infection. Based on the serological finding patients were classified as suffering from primary or secondary DF. A total of 1942(89.69\%) patients were classified as having primary dengue infection and only $182(8.4 \%)$ were classified as having secondary dengue infection out of the total seropositive cases (2165).

Comparison of platelet count and hepatic markers in patients with primary and secondary dengue infection reveals that platelet counts were significantly deranged ( $<<0.05$; 95\% CI 1.119 to 2.679.7) and Alkaline phosphatase levels were significantly higher in patients with secondary dengue infection than those having infection for the first time ( $<<0.05$; $95 \%$ CI 0.0768 to 0.6428 ). For all other parameters the difference in positivity between primary and secondary dengue infections was not statistically significant.

\section{Discussion}

Dengue viral infections are one of the most rapidly evolving vectors borne infections, which now affects 125 countries, causing approximately 100 million apparent infections each year [8]. Infection with DENV results in either undifferentiated viral fever, DF, DHF or DSS. Involvement of the liver leading to hepatic dysfunction is a well-recognized complication of dengue [9-11]. Dengue associated acute liver failure has a high mortality due to complications such as encephalopathy, severe bleeding, renal failure and metabolic acidosis $[9,10]$.
In our study the male to female ratio of dengue patients was $1.65: 1$ and the largest number of positive samples (32.74\%) were from the age-group 21-30 years. These findings are similar to those reported by NishatHussain Ahmed et al in their study wherein they have also reported male female ratio of 1.6:1 and preponderance of infection in the 20-30 years age group [12].

In this study, we have determined the changes in liver enzymes in patients suffering from acute dengue infection. ALT and AST are considered as indicators of 
lever cell injury as they are released into the circulation following liver cell injury [13]. Although ALT is also found in low concentrations in skeltol muscles, brain and intestinal tissue, it is predominantly considered to be a liver specific enzyme [25]. In contrast, AST is released following damage to liver, cardiac and skeletal muscles [13]. The important characteristic of hepatic involvement with dengue infection is greater elevation in AST than ALT levels, and distinguishes lever failure caused by dengue infection from that caused by other causes of infectious hepatitis [14].

We have also found rise in AST levels significantly higher than ALT in dengue patients and it is likely to have resulted from other sources apart from liver contributing to rise in serum AST levels [15].

In our study raised AST levels were fund in $78.3 \%$ of the patients and raised ALT levels in $55.6 \%$ of the patients. In majority of the studies, elevation of AST is more than ALT [16]. The increased AST /ALT ratio is useful for differential diagnosis from acute hepatitis caused by Hepatitis A,B or C viruses where it is rarely observed [17].

Hypoalbunemia has been seen in $32 \%$ of our patients while it ranges from $16.5-76 \%$ in various other studies $[5,18,19]$. The heterogeneity of the population and severity of disease may be responsible for such a wide range observed in various studies.

In this study we also assessed the changes in GGT, ALP, serum bilirubin and serum albumin levels. The levels of these were not found to be significantly deranged in dengue patients $(\mathrm{p}>0.05)$. These findings suggest that there was minimal cholestasis in patients and similar findings have been reported by S. Fernando et al[15].

Further in the study we have also compared the difference in liver enzymes in primary and secondary dengue infection. Transaminases (ALT, AST) were found to be abnormally increased in both primary and secondary dengue infection. However, there was no significant difference in the levels between primary and secondary dengue infected cases. Similar findings have also been reported by Wong et al [5].

The incidence of raised total bilirubin, raised ALP and thrombocytopenia was more significant in secondary dengue infection than in primary dengue infection. Total bilrubin was raised in $57 \%$ of the secondary

\section{Original Research Article}

dengue infected cases as compared to just $2 \%$ in primary cases $(\mathrm{p}<0.05)$ while ALP was raised in $50 \%$ of secondary dengue cases as against $11 \%$ of primary dengue cases $(\mathrm{p}<0.05)$. Similarly, thrombocytopenia was observed in $79 \%$ of secondary dengue cases as against $24 \%$ of primary dengue cases $(p<0.05)$. These findings corroborated with those reported by Bandaru et al [14].

\section{Conclusion}

Considering the above significant values, raised transaminases levels particularly AST may differentiate dengue infection from other febrile illness but may not differentiate primary dengue infection from secondary dengue infection. However, parameters such as total bilirubin, Alkaline phosphatase and platelet count may serve as early predictors for the differentiation of primary and secondary dengue infection Wahid et al[20].

To conclude the present study highlights the importance of biochemical markers in distinguishing dengue from other febrile illness and their role in identifying secondary and primary dengue cases. These findings have important public health implications in managing a case of dengue fever and handling of epidemics.

\section{Contribution of authors}

1. Dr. Iva Chandola: Principal Investigator

2. Dr. Brahmnish Sitara: helped with data collection

3. Dr. Nidhi Negi: prepared outline for the project

4. Dr. V. K. Kataria: guidance and proof reading

Findings: Nil; Conflict of Interest: None initiated Permission from IRB: Yes

\section{References}

1. New ed. Geneva, Switzerland: World Health Organization; 2009. World Health Organization (WHO). Dengue- Guidelines for Diagnosis, Treatment, Prevention and Control.

2. Guzman MG, Halstead SB, Artsob H, et al. Dengue: a continuing global threat. Nat Rev Microbiol. 2010 Dec; 8 (12 Suppl):S7-16. doi: 10.1038/nrmicro2460.

3. Linares EM, Pannuti CS, Kubota LT, et al. Immunospot assay based on fluorescent nanoparticles for Dengue fever detection. Biosens Bioelectron. 2013 Mar 15; 41:180-5. doi: 10.1016/j.bios. 2012. 08.005. Epub 2012 Aug 16. 
4. Hasan S, Jamdar SF, Alalowi $\mathrm{M}^{3}$, et al. Dengue virus: A global human threat: Review of literature. J Int Soc Prev Community Dent. 2016 Jan-Feb; 6(1):1-6. doi: 10. 4103 /2231-0762.175416.

5. Wong M, Shen E. The utility of liver function tests in dengue. Ann Acad Med Singapore. 2008 Jan; 37(1): 82-3.

6.Parkash O, Almas A, Jafri SM, et al. Severity of acute hepatitis and its outcome in patients with dengue fever in a tertiary care hospital Karachi, Pakistan (South Asia). BMC Gastroenterol. 2010 May 7;10:43. doi: 10. 1186/1471-230X-10-43.

7. World Health Organization, Special Programme for Research, Training in Tropical Diseases, World Health Organization. Department of Control of Neglected Tropical Diseases, World Health Organization. Epidemic, Pandemic Alert. Dengue: guidelines for diagnosis, treatment, prevention and control. World Health Organization; 2009.

8. Messina JP, Brady OJ, Pigott DM, et al. The many projected futures of dengue. Nat Rev Microbiol. 2015 Apr; 13 (4): 230-9. doi: 10.1038/nrmicro3430. Epub 2015 Mar 2.

9. Malavige GN, Ranatunga PK, Jayaratne SD, et al. Dengue viral infections as a cause of encephalopathy. Indian J Med Microbiol. 2007 Apr;25(2):143-5.

10. Trung DT, Thao le TT, Hien TT, et al. Liver involvement associated with dengue infection in adults in Vietnam. Am J Trop Med Hyg. 2010 Oct; 83 (4):774-80. doi: 10.4269/ajtmh.2010.10-0090.

11. Jayaratne SD, Atukorale V, Gomes L, et al. Evaluation of the WHO revised criteria for classification of clinical disease severity in acute adult dengue infection. BMC Res Notes. 2012 Nov 20;5:645. doi: 10. 1186/1756-0500-5-645.

\section{Original Research Article}

12. Ahmed NH, Broor S. Dengue fever outbreak in Delhi, North India: a clinico-epidemiological study. Indian journal of community medicine: official publication of Indian Association of Preventive \& Social Medicine. 2015 Apr;40(2):135.

13. Ozer J, Ratner M, Shaw M, et al. The current state of serum biomarkers of hepatotoxicity. Toxicology. 2008 Mar 20;245(3):194-205. doi: 10.1016/j.tox. 2007. 11.021. Epub 2007 Dec 5.

14. Bandaru AK, Vanumu CS. Early predictors to differentiate primary from secondary dengue infection in children.Medical Journal of Dr. DY Patil University. 2016 Sep 1;9(5):587.

15. Fernando S, Wijewickrama A, Gomes L, et al. Patterns and causes of liver involvement in acute dengue infection. BMC Infect Dis. 2016 Jul 8;16:319. doi: 10.1186/s12879-016-1656-2.

16. Kuo CH, Tai DI, Chang-Chien CS, et al. Liver biochemical tests and dengue fever. Am J Trop Med Hyg. 1992 Sep;47(3):265-70.

17. Samanta J, Sharma V. Dengue and its effects on liver. World J Clin Cases. 2015 Feb 16;3(2):125-31. doi: 10.12998/wjcc.v3.i2.125.

18. Saha AK, Maitra S, HazraSCh. Spectrum of hepatic dysfunction in 2012 dengue epidemic in Kolkata, West Bengal. Indian J Gastroenterol. 2013 Nov;32(6):400-3. doi: 10.1007/s12664-013-0382-6. Epub 2013 Sep 14.

19. Itha S, Kashyap R, Krishnani N, et al. Profile of liver involvement in dengue virus infection. Natl Med J India. 2005 May-Jun; 18 (3):127-30.

20. Wahid SF, Sanusi S, Zawawi MM, et al. A comparison of the pattern of liver involvement in dengue hemorrhagic fever with classic dengue fever. Southeast Asian J Trop Med Public Health. 2000 Jun; 31 (2): 259-63.

\section{How to cite this article?}

Chandola I, Sitara B, Negi N, Kataria V.K. Biomarkers as a diagnostic tool in primary and secondary dengue Infections. Trop J Path Micro 2019;5(1):37-42.doi:10.17511/jopm. 2019.i01.07. 